\title{
Permanência estudantil e autonomia universitária: a questão do SiSU no contexto de uma universidade estadual do interior da Bahia
}

\author{
Student permanence and university autonomy: the SiSU \\ issue in the context of a state university in the interior of Bahia
}

Daniel Cardoso Alves ${ }^{1}$

Marta Lorena Lima Brito

Resumo: Dentre as vinte e uma estratégias expressas no Plano Nacional de Educação (PNE) para a consecução da meta 12, a estratégia 12.5 associa a ampliação da política de permanência estudantil na educação superior com as políticas de acesso, inclusão, ações afirmativas e assistência estudantil, como forma de garantir o sucesso acadêmico aos estudantes desse nível de ensino. À luz dessa estratégia, o presente estudo tem como objetivo analisar a política de permanência estudantil adotada por uma universidade estadual do interior da Bahia diante do contexto de adesão ao Sistema de Seleção Unificada (SiSU), uma política de acesso externa à universidade e de abrangência nacional. Para tanto, o percurso metodológico constituiu-se de revisão bibliográfica, pesquisa documental e pesquisa de campo, cujos dados e informações levantados foram sistematizados e analisados por meio da técnica denominada análise de conteúdo. Dentre os resultados obtidos, constatou-se que, o acesso às políticas de permanência estudantil ainda é restrito, burocrático e tem pouca visibilidade na instituição, tendo em vista a existência de um perfil socioeconômico discente extremamente demandante. Contudo, a adesão a políticas atreladas à bandeira da democratização do acesso ao ensino superior, como forma de angariar recursos financeiros para a execução das ações de permanência estudantil na universidade, traz consigo a seguinte inquietação: o que é democratizar numa lógica em que ainda se faz necessário um processo de seleção para segregar? Esta é uma questão que, sem dúvida, não se esgotará neste estudo.

Palavras-chave: Democratização. Educação superior. Permanência estudantil. Plano Nacional de Educação. Sistema de Seleção Unificada (SiSU). 
Abstract: Among the twenty-one strategies expressed in the National Plan of Education (PNE) to achieve goal 12, strategy 12.5 associates the expansion of the policy of student stay in higher education with the policies of access, inclusion, affirmative action and student assistance, as a way to ensure academic success for students at this level of education. In light of this strategy, the present study aims to analyze the policy of student stay adopted by a state university in the interior of Bahia in the context of adherence to the Unified Selection System (SySU), a policy of external access to the university and comprehensiveness national. In order to do so, the methodological course consisted of bibliographic review, documentary research and field research, whose data and information were systematized and analyzed through the technique called content analysis. Among the results obtained, it was observed that access to student residence policies is still restricted, bureaucratic and has little visibility in the institution, due to the existence of an extremely demanding student socioeconomic profile. However, adherence to policies linked to the democratization of access to higher education, as a way to raise financial resources for the execution of student stay at university, brings with it the following concern: what is democratizing in a logic in which does a selection process need to be segregated? This is an issue that will undoubtedly not be exhausted in this study.

Keywords: Democratization. College education. Student stay. National Education Plan (PNE). Unified Selection System (SySU).

1 Universidade do Estado de Minas Gerais | Faculdade de Educação | Departamento de Fundamentos Sócio Históricos da Educação | Belo Horizonte | MG | Brasil. Contato: dca.uemg@gmail.com. ORCID: http://orcid.org/0000-0003-2088-8919

2 Universidade Estadual do Sudoeste da Bahia | Pró-Reitoria de Graduação | Secretaria Setorial de Cursos | Itapetinga | BA | Brasil. Contato: mllbrito@uesb.edu.br. ORCID: http://orcid.org/0000-0001-9198-2078

- Recebido em: 26 de março de 2019

- Aprovado em: 4 de maio de 2020

DOI: http://dx.doi.org/10.1590/S1414-40772021000100003

Este é um artigo publicado em acesso aberto sob uma licença Creative Commons

https://creativecommons.org/licenses/by-nc/4.0/ 


\section{Introdução}

A atual expansão e a suposta democratização da Educação Superior nas universidades estaduais brasileiras se sustentam em políticas empenhadas na garantia do acesso, da inclusão, da inserção de grupos desfavorecidos e da assistência estudantil. Essas políticas resultam, sobretudo, de instrumentos normativos que estabelecem as diretrizes para a educação superior no Brasil. Dentre esses instrumentos, a Constituição Federal, a Lei de Diretrizes e Bases da Educação e os Planos Nacionais de Educação (PNE) assumem o protagonismo teórico para a configuração do cenário da educação brasileira.

Das citadas disposições normativas, o PNE é o instrumento em que, a cada dez anos, se projeta, por meio de metas e estratégias, os objetivos para o êxito da educação brasileira em todos os seus níveis. O atual PNE passou a vigorar no ano de 2014 e estrutura-se de 20 (vinte) metas e 254 (duzentos e cinquenta e quatro) estratégias, as quais devem ser implementadas num prazo de dez anos. No que concerne à educação superior, a meta classificada, nesse Plano, como de número 12, diz respeito à elevação em $50 \%$ (cinquenta por cento) a taxa bruta de matrícula e, em 33\% (trinta e três por cento), a taxa líquida para da população de 18 (dezoito) a 24 (vinte e quatro) anos para 50\% (cinquenta por cento), ampliando, ainda, em pelo menos, $40 \%$ (quarenta por cento) as novas matrículas no segmento público superior. Para o seu alcance, são estabelecidas 21 (vinte e uma) estratégias, dentre as quais, a estratégia de ordem 12.5 refere-se, diretamente, ao objetivo deste estudo, que se constitui em analisar a política de permanência estudantil adotada por uma universidade estadual do interior da Bahia diante do contexto de adesão ao Sistema de Seleção Unificada (SiSU), uma política de acesso externa à universidade e de abrangência nacional.

Conforme a supracitada estratégia, a ampliação da taxa de permanência estudantil na educação superior deve estar associada a políticas de acesso, inclusão, ações afirmativas e assistência estudantil, como forma de garantir o sucesso acadêmico aos estudantes desse nível de ensino. No contexto da Universidade Estadual do Sudoeste da Bahia (UESB), que é o lócus deste estudo, constata-se que, a normatização interna dessas políticas teve o seu ciclo concluído no ano de 2012, considerando que: a primeira política implementada pela UESB data do ano de desde 2009, quando ela aderiu ao plano nacional de formação de professores da educação básica (Parfor), que tem como objetivo garantir a formação superior aos professores não portadores de diploma superior em atuação na rede pública; em 2006 vinculou-se à UAB, ofertando o seu primeiro curso na modalidade EaD, Licenciatura em Física; no ano de 2008, aprovou a sua resolução de reserva de vagas e cotas adicionais - Resolução CONSEPE n 37/2008 - (BAHIA, 
2008b), período em que, também, implantou o Programa de Ações Afirmativas, definindo na Resolução CONSEPE nº 36/2008 (BAHIA, 2008a), principalmente, as ações relacionadas ao sistema de reservas de vagas combinadas com quotas adicionais no concurso vestibular para os cursos de graduação da UESB (acesso e permanência) e, com base na Resolução CONSU 011/2008 (BAHIA, 2008c), disciplinou o seu Programa de Assistência Estudantil; e em 2012 aderiu ao SiSU como forma de ingresso paralela ao vestibular nos seus cursos de graduação.

Essa trajetória das políticas educacionais internas na UESB justifica o recorte temporal adotado no estudo (2012 a 2016), sendo que o ano de 2016, devido a suspensões de períodos letivos, equivale ao ano civil de 2017, o qual diz respeito, justamente, ao último Censo da Educação Superior, considerando que, segundo o cronograma fixado na Portaria INEP Nº 945, de 26 de outubro de 2018 (BRASIL, 2018), os dados referentes ao Censo de 2018 somente serão divulgados no dia 19 de setembro de 2019. O ano limite do recorte temporal também se justifica por referir-se ao primeiro terço do prazo decenal para a implementação das ações traçadas no PNE de 2014.

Para a análise da política de permanência estudantil adotada na UESB, os seus 47 (quarenta e sete) cursos de graduação são objeto deste estudo, cujos dados coletados na etapa da pesquisa de campo no âmbito da Pró-Reitoria de Extensão e Assuntos Comunitários (PROEX), quando complementados pela entrevista aberta realizada com a respectiva próreitora $^{1}$, preencheram lacunas da etapa da pesquisa documental, o que contribuiu significativamente para uma fidedigna sistematização quantitativa dos dados, bem como, para a posterior análise qualitativa dos mesmos por meio da técnica denominada análise de conteúdo (BARDIN, 1991). A intenção deste estudo é que, as reflexões expressas contribuam para a avaliação das políticas de permanência estudantil por parte de outras universidades empenhadas no alcance, efetivo, da estratégia 12.5 estabelecida no PNE em vigência.

Assim, este artigo organiza-se em três seções, além desta introdução e das considerações finais. Na seção 1, é realizada uma breve revisão de literatura filosófica sobre autonomia universitária que embasa a temática do estudo. Na sequência, é exposta a metodologia da pesquisa. E a terceira seção é destinada à apresentação e interpretação dos resultados obtidos.

\footnotetext{
${ }^{1}$ Entrevista aberta realizada no dia 29 de novembro de 2017, viabilizada por contatos telefônicos e trocas de $e$ mails institucionais e consentida por autorização eletrônica da secretaria da Pró-Reitoria de Extensão e Assuntos Comunitários (PROEX) através do e-mail institucional proex@uesb.edu.br. Aceite em participar da pesquisa obtido em: em 24 de novembro de 2017.
} 


\section{Fundamentação teórica}

A questão da autonomia universitária e democratização do ensino face à padronização nacional da forma de acesso ao Ensino Superior: o SiSU

A contemporaneidade brasileira é reveladora de que a Universidade, na condição de organização social, isto é, como "entidade operacional determinada por sua instrumentalidade administrativa" (CHAUÍ, 2003, p. 24), por meio da qual a educação superior se realiza, não é o que, enquanto instituição social, que "aspira à Universidade. Tem a sociedade como seu princípio" (CHAUÍ, 2003, p. 24), deveria ser ou, ao menos, caminha em descompasso com a missão institucional de promover a transformação social por meio da educação, objetivando a formação de profissionais-cidadãos comprometidos com o desenvolvimento da sociedade e do país. Concebida como organização, a Universidade regride a uma gênese marcada pela segregação social e vulnerabilidade de sentido. A respeito dessa incongruência, Fávero (2006) possibilita uma compreensão dialética, ao lembrar que a Universidade "foi criada não para atender às necessidades fundamentais da realidade da qual era e é parte, mas pensada e aceita como um bem cultural oferecido a minorias, sem uma definição clara no sentido [...]” (p. 19).

Reduzida à condição de organização social, logo, entidade administrada, é pacífica a compreensão de Universidade como produto indefinido de sentido pautado na manutenção de um status quo, na "garantia das estruturas dominantes", segundo Marx (2011). Todavia, ao passar da condição de organização social para a de instituição social, é inconcebível que a Universidade não assuma um sentido social amplo; não se invista do papel social que vai muito além da mera função de "letramento", historicamente a ela atribuída; não integre a vida social de forma constante, plena e permanente; e não se apresente como um instrumento singular da sociedade capaz de desvelar mazelas e contribuir para a transformação de possibilidades em realizações humanamente efetivas.

\footnotetext{
Em outras palavras, a instituição se percebe inserida na divisão social e política e busca definir uma universalidade (ou imaginária ou desejável) que lhe permita responder às contradições impostas pela divisão. Ao contrário, a organização pretende gerir seu espaço e tempo particulares aceitando como dado bruto sua inserção num dos pólos da divisão social, e seu alvo não é responder às contradições e sim vencer a competição com supostos iguais (CHAUÍ, 2001, p. 188).
}

Contaminada pela lógica neoliberal contemporânea, a educação superior e, por conseguinte, a Universidade, distancia-se da função questionadora da sua razão de ser (ensino, pesquisa e extensão), cumprindo, desta forma, fidedignamente um papel atrelado aos ditames 
do Capital, em que "[...] No conceito do capital está contido o capitalista” (MARX, 2011, p. 256 [...] 422), ou seja, de organização “operacional, produtivista e flexível” (CHAUÍ, 2001, p. 191).

Diante desse cenário, não é estranho o fato de que políticas educacionais voltadas para o acesso e a permanência no ensino público superior, ainda engatinhem na implementação de ações para a inserção da grande "massa" historicamente reprimida em nosso país. Prova disso é que, somente nas últimas duas décadas, tem se verificado, de forma mais intensa, a criação de normativas oficiais para a ampliação do acesso e da permanência estudantil no ensino superior. Todavia, essas normativas, em seu conjunto, investem-se de um cunho extremamente capitalista de se pensar a educação brasileira, uma vez que estão, notadamente, orientadas para formas de financiamento de ingressos no setor privado do ensino superior, ao tempo em que, ao seguimento público, restam medidas paliativas de suposta democratização de garantia do acesso ao ensino superior público, atreladas a ações de inclusão e permanência insuficientes, para grupos sociais tradicionalmente excluídos desse nível de ensino no país.

A lógica da expansão e a eventual democratização da educação superior estão presentes nas políticas educacionais brasileiras, que se apresentam como as principais no contexto educacional da atualidade, são elas: a Universidade Aberta do Brasil (UAB) instituída em 2006 por força do Decreto Federal n⿳ 5.800, de 08 de junho de 2006 (BRASIL, 2006); o Programa Nacional de Assistência Estudantil (PNAES), instituído em 2010 pelo Decreto ${ }^{\circ}$ 7.234, de 19 de julho de 2010 (BRASIL, 2010); o Sistema de Seleção Unificada (SiSU) (BRASIL, 2017), criado em 2010 pela Portaria Normativa MEC n 2, de 26 de janeiro de 2010, alterada pela Portaria Normativa MEC n 21, de 05 de novembro de 2012; e as Ações Afirmativas instituídas em 2012 por meio da Lei Federal n 12.711, de 29 de agosto de 2012 (BRASIL, 2012), e regulamentada pelo Decreto Federal n $n^{\circ} 7.824$, de 11 de outubro de 2012.

No que concerne à instituição da UAB, o principal objetivo do governo consiste em aumentar o alcance do ensino superior no país, interiorizando-o e diminuindo as desigualdades regionais das ofertas. Em outras palavras, é uma estratégia da política educacional fixada na meta 12 do PNE, cujos objetivos diretamente relacionados são:

12.1) otimizar a capacidade instalada da estrutura física e de recursos humanos das instituições públicas de educação superior, mediante ações planejadas e coordenadas, de forma a ampliar e interiorizar o acesso à graduação; 12.2) ampliar a oferta de vagas, por meio da expansão e interiorização da rede federal de educação superior, da Rede Federal de Educação Profissional, Científica e Tecnológica e do sistema Universidade Aberta do Brasil, considerando a densidade populacional, a oferta de vagas públicas em relação à população na idade de referência e observadas as características regionais das micro e mesorregiões definidas pela Fundação Instituto Brasileiro de Geografia e 
Estatística - IBGE, uniformizando a expansão no território nacional; [...] (BRASIL, 2014).

Vinculada, na atualidade, ao SiSU, a Política de Assistência Estudantil no Brasil, com vistas à permanência do estudante na universidade, vem se reinventando ao longo do tempo, com avanços e retrocessos e, hoje, apesar de ser um dever do estado fixado na Constituição Federal de 1988 e constituir-se como um Programa de governo, engatinha a passos largos de garantir, efetivamente, que o estudante universitário socioeconomicamente desfavorecido consiga se manter na universidade até a conclusão do seu curso.

Instituído a menos de uma década, o PNAES, restrito às IES que adotam o SiSU como forma de acesso dos estudantes aos seus cursos, atualmente é o principal norteador para a construção das políticas de assistência aos estudantes de graduação. Contudo, os objetivos estabelecidos nesse Programa (democratizar as condições de permanência dos jovens na educação superior pública federal, minimizar os efeitos das desigualdades sociais e regionais na permanência e conclusão da educação superior, reduzir as taxas de retenção e evasão e contribuir para a promoção da inclusão social pela educação) não são ensejos recentes, pelo contrário, resultam de históricas lutas estudantis.

Dentre essas lutas, a Casa do Estudante do Brasil, fundada, no ano de 1929, de maneira autônoma por um grupo de estudantes universitários, cujo objetivo principal era a busca pela assistência social estudantil, sem dúvida, apresenta-se como um exemplo histórico da pressão social por políticas de assistência estudantil, imprescindíveis à permanência do estudante desfavorecido socioeconomicamente na universidade, sem as quais não terá ele as condições mínimas para trilhar a sua trajetória curricular e alcançar o êxito na sua formação, fadando-se ao cursus determinista de abandonar o seu tão sonhado curso, tendo em vista que,

Se o êxito no nível mais alto do cursus permanece muito fortemente ligado ao passado escolar mais longínquo, há que se admitir que as escolhas precoces comprometem muito fortemente as oportunidades de atingir tal ou tal ramo do ensino superior e de nele triunfar. Em síntese, as cartas são jogadas muito cedo (BOURDIEU, 1998, p. 52).

Nesse interim, como parte do projeto político educacional do governo de Getúlio Vargas, a assistência estudantil materializou-se na Constituição Federal de 1934. No seu artigo 157, preconizava a doação de fundos a estudantes necessitados, por meio do fornecimento de material escolar, bolsa de estudo, assistência alimentar, médica e odontológica. Com o apoio do Ministério da Educação, em agosto de 1938, a Casa do Estudante do Brasil realizou o $1^{\circ}$ Conselho Nacional de Estudantes, conseguindo consolidar o almejado projeto de criar a 
entidade máxima de representação dos estudantes: a União Nacional dos Estudantes (UNE). Entretanto, desvinculou-se do seu objetivo principal, restringindo suas ações a eventos culturais na cidade do Rio de Janeiro, onde, em 1942, estabeleceu a sua sede.

$\mathrm{Na}$ atual configuração do perfil do estudante do ensino superior, uma questão não pode ser desconsiderada: as mudanças ocorridas nas universidades brasileiras, cujas expansão da oferta de vagas nos cursos superiores, a inserção de novas formas de seleção, ações afirmativas como a adoção da lei de cotas, mudaram o perfil socioeconômico do estudante universitário propiciada, o que demanda a necessidade de reformulação das ações e políticas de permanência na universidade, pois, estudos sobre evasão apontam que, a promoção de ações de assistência estudantil a diminuem consideravelmente o que, como efeito consequente, aumentam a probabilidade de conclusão do curso por aquele estudante historicamente excluído do ensino superior.

Como nova forma de acesso ao ensino superior, o SiSU, segundo o Ministério da Educação (MEC), iniciado no ano de 2009, tem como finalidade selecionar os candidatos às vagas das instituições públicas de ensino superior por meio da nota do Exame Nacional do Ensino Médio (Enem). As instituições de ensino, por sua vez, obrigam-se a efetuar sua adesão ao sistema em todas as edições, através dos editais de chamamento, e assinar o termo de adesão, no qual constam todas as informações necessárias referentes aos cursos, vagas e critérios de seleção dos candidatos. A seleção é feita por um sistema informatizado com base na nota obtida pelo candidato no Enem. No portal eletrônico do SiSU, os candidatos podem consultar as vagas disponíveis, pesquisando as instituições e os respectivos cursos participantes.

O SiSU constitui-se na estratégia classificada como 12.16 do PNE - "consolidar processos seletivos nacionais e regionais para acesso à educação superior como forma de superar exames vestibulares isolados" (BRASIL, 2014), que vincula-se ao PNAES e à política de ações afirmativas no ensino superior, logo, à estratégia 12.5 analisada neste estudo, uma vez que, as instituições dele participantes têm em contrapartida a disponibilização de recursos financeiros direcionados para as ações de assistência estudantil. Ao mesmo tempo, o candidato inscrito no SiSU por meio da política de ações afirmativas, tem a possibilidade de concorrer a vagas reservadas, seguindo as definições contidas na portaria normativa que institui essa política nacional de acesso. Os estudantes que optam por concorrer às vagas reservadas em decorrência do disposto na Lei n 12.711 , de 2012, e regulamentação em vigor, são classificados dentro de cada grupo e subgrupo de inscritos e fazem jus ao atendimento pelo PNAES.

A respeito da política de ações afirmativas, é interessante observar que, diferentemente da UAB e do SiSU, que foram políticas iniciadas no âmbito federal e posteriormente absorvidas 
pelas IES estaduais, esta se deu numa lógica inversa, ou seja, segundo Guimarães (2003), universidades estaduais do Rio de Janeiro e da Bahia, respectivamente nos anos de 2002 e 2003, estabeleceram legislações próprias sobre cotas raciais e oriundos de escolas públicas, incentivando que outras IES estaduais passassem, por meio dos seus próprios conselhos universitários e/ou leis estaduais, também a acrescentarem outras ações afirmativas, tais como, as voltadas para estudantes de baixa renda, indígenas, quilombolas e pessoas com deficiência, implementando-as nos seus processos seletivos antes mesmo da existência de uma legislação federal, a qual somente veio existir dez anos depois e sob muita pressão social, especialmente, por parte do movimento negro.

A política de ações afirmativas é tão importante para a consecução da meta 12 do PNE, concernente ao ensino superior, que se configura em quatro das vinte e uma estratégias traçadas para o alcance dessa meta:

12.5) ampliar as políticas de inclusão e de assistência estudantil dirigidas aos (às) estudantes de instituições públicas, bolsistas de instituições privadas de educação superior e beneficiários do Fundo de Financiamento Estudantil - FIES, de que trata a Lei $\mathrm{n}^{-} \mathbf{1 0 . 2 6 0}$, de 12 de julho de 2001, na educação superior, de modo a reduzir as desigualdades étnico-raciais e ampliar as taxas de acesso e permanência na educação superior de estudantes egressos da escola pública, afrodescendentes e indígenas e de estudantes com deficiência, transtornos globais do desenvolvimento e altas habilidades ou superdotação, de forma a apoiar seu sucesso acadêmico; [...] 12.9) ampliar a participação proporcional de grupos historicamente desfavorecidos na educação superior, inclusive mediante a adoção de políticas afirmativas, na forma da lei; 12.10) assegurar condições de acessibilidade nas instituições de educação superior, na forma da legislação; [...] 12.13) expandir atendimento específico a populações do campo e comunidades indígenas e quilombolas, em relação a acesso, permanência, conclusão e formação de profissionais para atuação nessas populações; [...] (BRASIL, 2014).

Não obstante os avanços verificados ao longo da implementação dessas políticas de ampliação do acesso ao ensino superior, as quais são inseparáveis do conjunto de ações que contribuem para a permanência e, o consequente, êxito do ingressante, sobretudo, daquele socioeconomicamente desfavorecido, os relatórios institucionais sobre acesso, evasão e integralização são, por demais, preocupantes por retratarem estatisticamente o quanto o ensino público superior está distante dos objetivos expressos nos documentos oficiais.

$\mathrm{O}$ acesso ao ensino público superior ainda restrito, se comparado à demanda social e, ao mesmo tempo, os baixos índices de integralização curricular e os altos índices de evasão nas IES, revelam a necessidade de maiores esforços, tanto no que se refere à intensificação das ações, quanto em relação a adoção de reformulação e/ou novas estratégias sociais, a fim de se reverter esses índices, os quais, quando analisados, parecem representar um cursus determinista 
em que, justamente aqueles sujeitos historicamente impedidos do acesso à universidade, após ingressarem, são os primeiros a abandonarem os seus cursos (TEIXEIRA, 1954, p. 55).

Esse cursus reforça a tese de que, as políticas educacionais somente surtirão efeitos positivos se pensadas e implementadas numa perspectiva de complementaridade, ou seja, aumentar o acesso sem a garantia de permanência por meio da assistência estudantil, resultará em mais evasão, da mesma forma que, possibilitar o ingresso na universidade de grupos historicamente excluídos do ensino superior a partir da implementação de ações afirmativas, como a lei de cotas, sem oferecer as condições socioeconômicas para que esses grupos trilhem sua trajetória acadêmica, é o mesmo que já pré-determinar que eles estão fadados, em breve tempo, a evadirem-se dos bancos universitários.

À luz de Teixeira (1954), diferentemente do que a análise imediatista permite enxergar, as causas da evasão são multifatoriais (HUNT, 2008; WITTE et al., 2013), cujos fatores como a reprovação e a repetência, apontados como centrais para o insucesso escolar desde os anos elementares do ensino, somente podem ser compreendidos em sua complexidade quando associados às vulnerabilidades socioeconômicas que afetam, principalmente, os grupos historicamente marginalizados. Nesse sentido, infere-se que, a evasão do estudante universitário se constitui como uma exclusão educacional iniciada nos anos elementares e fundamentais que, cíclica, se repete nos anos superiores do ensino.

É nesse histórico contexto de exclusões que se inserem as políticas educacionais de reforma e expansão da educação superior no Brasil, a qual se configura numa arena de interesses e conflitos, especialmente por se tratar de uma esfera que possibilita ascensão social e econômica, cuja marca característica, de um estado neoliberal, é a manutenção da estrutura social desigual. Essas políticas, ainda que orientadas para a sustentação desse estado, contribuíram para um novo perfil estudantil no ensino superior, uma vez que, ingressar em uma universidade pública sempre foi privilégio das classes mais favorecidas economicamente, justamente, por ser o ensino superior orientado exclusivamente para a elite.

Produtos das intensões de um estado neoliberal, as políticas educacionais de acesso e permanência no ensino superior evidenciam a dependência financeira das universidades públicas, as quais, como forma de sobrevivência, relativizam a conquistada autonomia didáticofinanceira, administrativa e de gestão financeira e patrimonial constitucionalmente assegurada no artigo 2017 da Constituição Federal brasileira de 1988, considerando a necessidade do repasse financeiro das verbas públicas, o que atrela suas políticas internas aos desígnios dos governantes e não necessariamente aos interesses dos principais sujeitos da universidade. 
Consequentemente, a autonomia, princípio da Universidade, logo, essencial para a sua razão de ser, como se destaca:

\begin{abstract}
Importante observar a precisão dos termos: "as universidades gozam de autonomia [...] e obedecerão ao princípio [...]". Os verbos imperativos. Em sua acepção própria, o vocábulo princípio traduz a ideia "de origem, começo, causa primária" [...]. E esta "é a ideia que está presente na expressão princípio de autonomia universitária a designar não um princípio constitucional ou uma norma constitucional de princípio norma programática-, mas um princípio universitário, ou mesmo de direito educacional por ser inerente à atividade universitária, e não à ordem jurídica, no sentido de orientação axiológica para a compreensão do sistema jurídico nacional" [...]. Assim entendida, a autonomia é causa primária da atividade universitária e é nesse sentido que deve ser compreendida a expressão "princípio de autonomia" [...] (FÁVERO, 1998, p. 61).
\end{abstract}

Deixa de ser uma capacidade de auto-organização da universidade no que concerne à aplicação dos recursos, planejamento das atividades e orientações das políticas internas da maneira mais conveniente à sua realidade (RANIERI, 1994) e passa a ser negociada, como ocorreu, de forma evidente, quando da recente adesão ao SiSU pelas universidades públicas, em que o recebimento de recursos federais, que seriam repassados às IES de acordo com o número de vagas por elas disponibilizadas, as levou a aderirem a uma política externa de seleção seduzidas, em sua maioria, pela vantagem financeira.

Pelo exposto, a questão da autonomia universitária e, por conseguinte, a sua razão de ser enquanto instituição social, apresenta-se frágil a partir do momento que é moldada com base em interesses externos que, se não absorvidos, a sucumbirão. A forma como muitas IES aderiram ao SiSU, por exemplo, evidencia tal fragilidade, dado o fato de que, sendo uma política externa à universidade, esta passa à condição de mera espectadora.

\title{
3 Metodologia
}

Com o objetivo de analisar a política de permanência estudantil adotada por uma universidade estadual do interior da Bahia, de natureza multicampi, com sede no município de Vitória da Conquista, diante do contexto de adesão ao SiSU, uma política de acesso externa à universidade e de abrangência nacional, a pesquisa se estrutura em quatro etapas: revisão bibliográfica, pesquisa de campo, pesquisa documental e sistematização e análise dos resultados, os quais foram interpretados por meio da técnica análise de conteúdo.

O recorte temporal, como já mencionado incialmente, tem como parâmetros o ano de conclusão das novas políticas educacionais de acesso, inclusão, permanência e assistência estudantil adotadas pela UESB, o último Censo da Educação Superior divulgado (BRASIL, 2017), o descompasso do período letivo na IES com o ano civil, e o primeiro terço de execução 
do PNE em vigência. Assim, o recorte temporal de análise dos dados corresponde aos anos de 2012 e 2016.

No que concerne aos procedimentos metodológicos, foram adotadas quatro etapas com base nas recomendações necessárias para estudos de casos (GIL, 2008):

a) Revisão bibliográfica acerca da relação entre autonomia universitária e a trajetória das políticas educacionais no Brasil, notadamente aquelas relacionadas à permanência estudantil. Essa revisão trouxe à baila as contribuições filosóficas e sociológicas para campo da educação dos seguintes teóricos: Bourdieu (1998), Chaui (2001; 2003), Fávero (1998; 2006), Guimarães (2003), Hunt (2008), Khondker (2004), Lopes (2002), Marx (2011), Ranieri (1994), Teixeira (1954) e Witte (2013);

b) Pesquisa documental no âmbito das instâncias administrativas da UESB, por meio de levantamentos, consultas e leituras dos documentos institucionais oficiais, dentre eles, o Plano de Desenvolvimento Institucional - PDI 2013-2017 (BAHIA, 2013) e as Resoluções que abordam sobre as políticas educacionais internas, bem como, por meio de consultas sistemáticas aos blogs, sites de notícias e outras redes sociais relacionadas à Universidade, buscando-se observar, no período de 2012 a 2016, do ponto de vista discursivo, a situação e o direcionamento das políticas educacionais adotadas e concernentes à permanência estudantil nos cursos de graduação da UESB;

c) Pesquisa de campo (coleta de dados e informações), cujo sujeito protagonista da pesquisa foi a Pró-Reitora de Extensão e Assuntos Comunitários da UESB. Para tanto, utilizou-se o seguinte instrumento: entrevista aberta com o apoio de roteiro, de caráter aprofundado, abordando as apreensões da Pró-Reitora, do ponto de vista da gestão, sobre as implicações do SiSU, enquanto nova política de acesso adotada pela Universidade, na sua política de permanência estudantil.

d) $\mathrm{O}$ tratamento dos dados equivaleu à quarta etapa da pesquisa e teve como finalidade a sistematização e análise qualitativas da multiplicidade dos significados impressos na entrevista realizada, valendo-se, para tanto, da técnica análise de conteúdo (BARDIN, 1991), em que os conteúdos resultantes da entrevista, ao complementarem as fontes documentais e os dados levantados, preenchem lacunas importantes para a maior compreensão das singularidades da temática em estudo.

\section{Resultados}

\subsection{Perfil do estudante de graduação da UESB}

De acordo com os dados fornecidos pela instituição por meio do sistema acadêmico adotado, o Sagres, a UESB acumula, de 2012 a 2016, um total de 11.336 (onze mil, trezentos e trinta e seis) estudantes, dos quais, $85 \%$ (oitenta e cinco por cento) ingressaram por meio dos processos seletivos Vestibular e SiSU. Do total de estudantes, $80 \%$ (oitenta por cento) são oriundos de escolas públicas, como se constata no gráfico 1: 
Gráfico 1 - Ingressantes pelo SiSU e Vestibular e por escola de origem 2012-2016

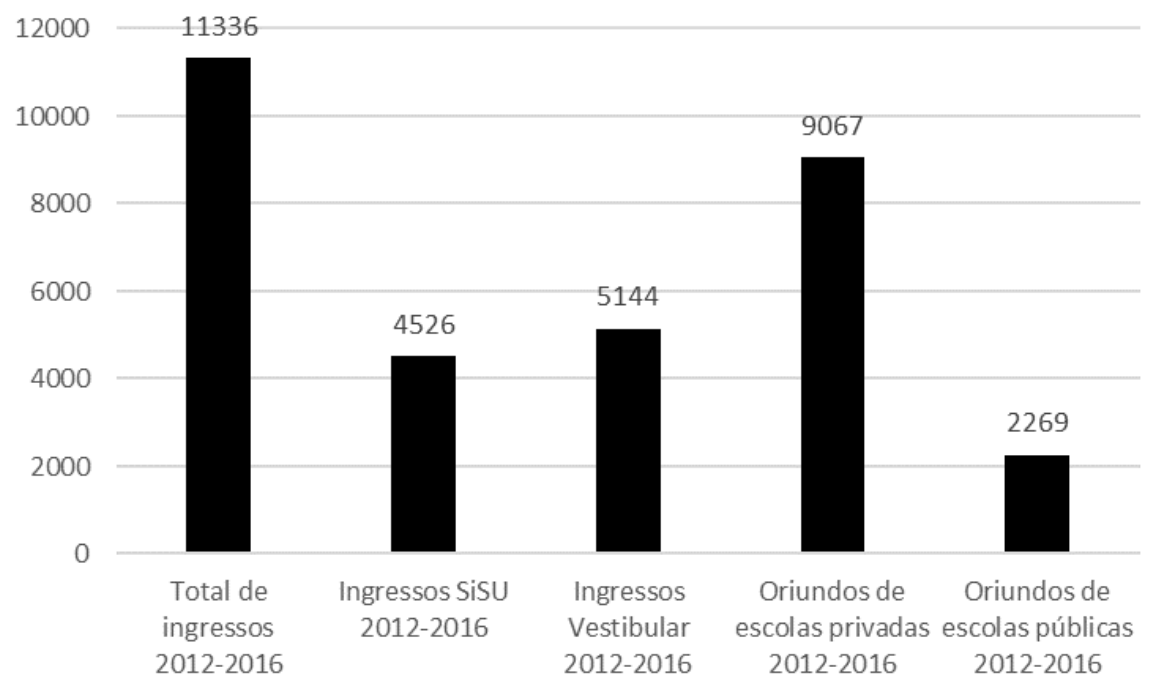

Fonte: Elaborado pelos autores com os dados da pesquisa.

Conforme se verifica no gráfico 2, abaixo, dos 9.670 (nove mil, seiscentos e setenta) estudantes que ingressaram pelos processos Vestibular e SiSU, aproximadamente $4 \%$ são cotistas adicionais, ou seja, ingressaram por meio da política de cotas para candidatos indígenas, quilombolas e deficientes, $50 \%$ (cinquenta por cento) ingressaram por meio da política de reserva de vagas destinadas àqueles candidatos oriundos de escolas públicas (30\%) ou que, além de terem estudado o ensino fundamental e médio na rede pública de ensino do Brasil, se autodeclaram pretos ou pardos (70\%) e 91\% (noventa e um por cento) são naturais do estado da Bahia.

Gráfico 2 - Ingressantes pelo SiSU e Vestibular por modalidade de ingresso e estado de origem 2012-2016

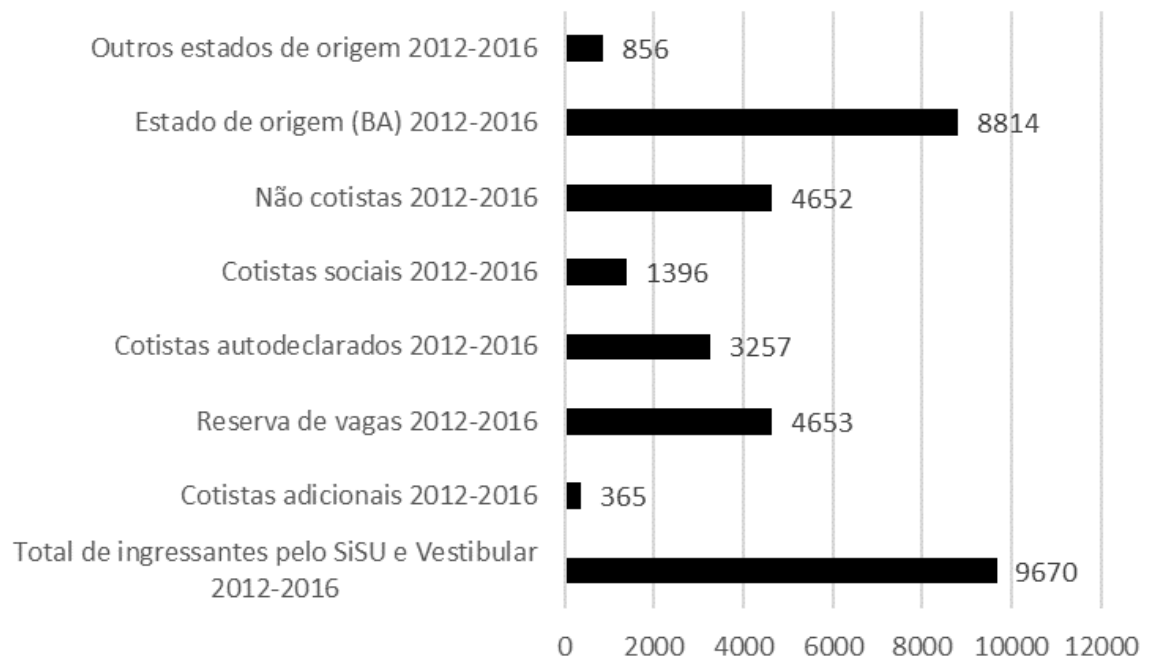

Fonte: Elaborado pelos autores com os dados da pesquisa. 
Quanto aos aspectos da permanência e integralização, ilustrados no gráfico 3, nota-se que, $50 \%$ (cinquenta por cento) dos estudantes que ingressaram por meio do Vestibular e SiSU são concluintes regulares, sendo que, apenas 3\% (três por cento) são provenientes do SISU, ao mesmo tempo em que, dos $29 \%$ (vinte e nove por cento) evadidos, $55 \%$ (cinquenta e cinco por cento) ingressaram na UESB pelo SiSU.

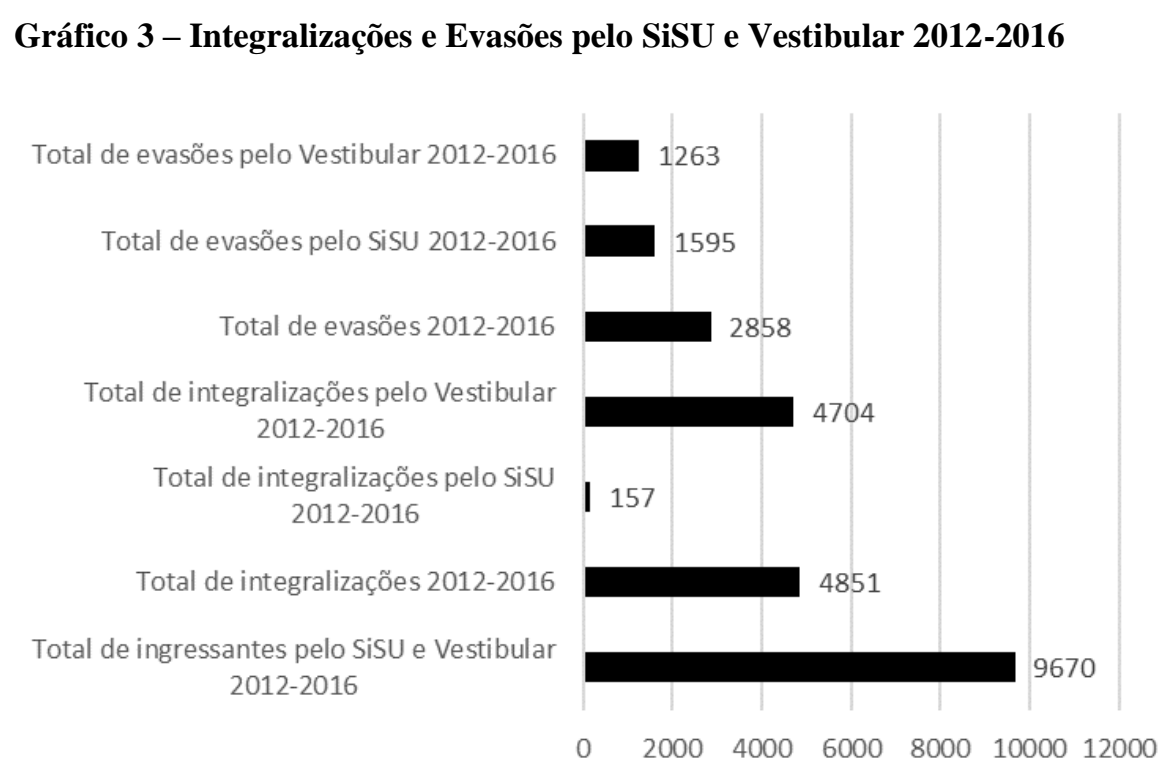

Fonte: Elaborado pelos autores com os dados da pesquisa.

A análise desses dados evidencia um perfil estudantil majoritariamente natural do estado da Bahia, oriundo de escola pública, constituído por um pouco mais da metade $(54 \%)$ de cotistas, $47 \%$ (quarenta e sete por cento) ingressantes pelo SiSU, aproximadamente 1/3 (um terço) que ingressa por meio do Vestibular e do SiSU evadem, sendo essa evasão superior em $5 \%$ (cinco por cento) no SiSU, e metade dos ingressantes não conclui o curso no tempo mínimo de integralização previsto nos projetos pedagógicos dos cursos (em média, quatro anos para cursos de nível de licenciatura e cinco anos para cursos de nível de bacharelado). A respeito do baixo percentual de integralizações verificado no SiSU (três por cento), esclarece-se que, para muitas turmas, dado o ano de início do SiSU na UESB, as integralizações encontravam-se em curso durante a coleta dos dados da pesquisa.

Por esse perfil, é imprescindível a existência de uma eficaz política de permanência estudantil numa universidade de maioria discente proveniente de escola pública, em que a metade é cotista, com integralização curricular irregular e que registrou, ao longo de cinco anos, um terço de evasões. 


\title{
4.2 Permanência e assistência estudantil na UESB sob o olhar da gestão
}

O Programa de Assistência Estudantil da UESB (PRAE) foi criado pela Resolução do CONSU N N $^{\circ} 11 / 2008$, com a perspectiva de assegurar a permanência e o êxito acadêmico dos alunos matriculados nos cursos de graduação mantidos pela instituição, cujos objetivos gerais estabelecidos no capítulo II, art. $2^{\circ}$, são:

\begin{abstract}
I. contribuir para a garantia de permanência e conclusão de curso dos estudantes da graduação da UESB, que comprovem carência econômica e social segundo critérios adotados pela Instituição, na perspectiva de inclusão social; formação integral; produção e difusão de conhecimento; e melhoria do desempenho acadêmico, qualidade de vida e bem-estar social; II. Garantir a alocação anual dos recursos orçamentários; III. Estimular a captação de recursos orçamentários para financiamento da assistência estudantil, a ser regulamentado pelo CONSU (BAHIA, 2008c).
\end{abstract}

Essa Resolução, de forma vinculada às resoluções que dispõem sobre o Programa de Ações Afirmativas (Resolução CONSEPE n 36/2008) e sobre o Sistema de Reserva de Vagas e Cotas Adicionais (Resolução CONSEPE n 37/2008 e suas alterações), vem orientando as ações institucionais para a consecução dos objetivos previstos nos incisos I e II supramencionados. Ao mesmo tempo, a adesão ao SiSU, no ano de 2012, como política de acesso à Universidade, apresenta-se como estratégia para o alcance do objetivo referente ao inciso III, uma vez que, os recursos financeiros advindos do Programa Nacional de Assistência Estudantil (PNAES) são consequentes da adesão a essa política.

O SiSU, assim, não somente representa uma mudança na forma de acessar a universidade pública, como evidencia orçamentos universitários demasiadamente comprometidos e insuficientes para o atendimento das demandas de permanência e assistência estudantil na universidade. Diante dessa realidade, a possibilidade de auxílio financeiro por meio da adesão a uma política nacional de acesso é extremamente sedutora para as IES que sofrem com os reduzidos números orçamentários.

A esse respeito, a Pró-Reitora da PROEX, sujeito protagonista desta pesquisa, entende que o SiSU e as políticas de permanência, assistência estudantil e ações afirmativas são complementares entre si e vieram para facilitar o acesso às universidades, sobretudo daquelas pessoas que não tinham condições de ingressar via vestibular, apresentando-se, assim, como uma das formas de garantir a democratização do acesso ao ensino superior. Além disso, por meio da adesão ao SiSU, as universidades passaram a ter direito ao recurso financeiro proveniente do PNAEST, o que tem facilitado, tanto as ações de permanência, quanto as ações de assistência estudantil na UESB. 
Com o recurso do PNAEST, associado aos recursos próprios da instituição, temos dado subsídio para a residência estudantil, aquisição de material odontológico, material para os centros acadêmicos, auxílio transporte, manutenção e ampliação do conjunto de cursos livres, em função da melhoria do desempenho acadêmico dos alunos, etc. A maioria dos alunos habilitados tem cota de xérox, conseguem a participação em eventos tanto nacionais, quanto internacionais. O recurso é usado também para equipar residência universitária, e subsídio para o restaurante universitário. É destinado a todos os alunos habilitados no PRAE independente da forma de ingresso, inclusive, para os atendimentos com a equipe multidisciplinar de psicólogos, pedagogos e assistentes sociais, que atendem nos três campi da UESB. Essa equipe é extremamente importante diante das mudanças que tivemos desde a criação da lei de cotas e da adesão ao SiSU, em que, temos recebido um grande número de alunos com deficiência nas disciplinas quantitativas, em leitura e interpretação, hoje aqui na universidade nós temos cursos para fazer um balizamento desses alunos, dessas disciplinas de Matemática, Física e Química, por que a deficiência vem desde o Ensino Médio e quando chegam à universidade se prolongam. Os alunos contam, também, com a disponibilização de vagas na creche institucional para os seus filhos e com os diversos cursos livres do PRAE, como o curso de inglês e espanhol para os alunos que farão intercâmbio e mobilidade estudantil. Enfim, são diversas ações no sentido de auxiliar esses alunos, sendo a busca pelo diálogo primordial para conhecimento das demandas (Entrevista em: 29/11/2017).

A Pró-Reitora esclarece, também, que é prematuro afirmar que o SiSU é a melhor maneira de ingresso e que resolverá, por meio da contrapartida financeira obtida com a sua adesão, todos os problemas relacionados à permanência exitosa dos estudantes na universidade, pois, a partir do momento que se aumenta essa chance de ingresso, outros problemas começam a surgir, os quais, dizem respeito, tanto aos aspectos socioeconômicos, quanto a questões relacionadas à formação básica, e se evidenciam no ensino superior.

Boa parte desses alunos chega apresentando muita dificuldade de aprendizagem, e acredito que é um dos motivos para o grande número de evasão desse público do SiSU, falta de base e falta de políticas por parte da universidade em tentar suprir essas dificuldades (Entrevista em: 29/11/2017).

Por fim, na concepção Pró-Reitora, todas as universidades caminham para essa forma de acesso, o SiSU, por acreditam ser a mais democrática na atualidade. É um sistema unificado em que todos concorrem nas mesmas condições a vagas para qualquer lugar no Brasil. A prova é única, o candidato pode escolher a universidade de acordo com a nota obtida no Enem, inclusive, sendo-lhe possível mudar de opção institucional durante o período de submissão da inscrição. Entretanto, essa nova forma de acesso ao ensino superior traz consigo muitas demandas para a universidade, que precisam de novas estratégias e políticas de permanência e assistência estudantil.

Nesse sentido, as universidades, ao adotarem uma forma nacional de seleção do seu corpo discente, passam a enfrentar novos desafios, em especial, aqueles advindos com a ultrapassagem das barreiras do regionalismo cultural, pedagógico e econômico. Com isso, a 
pluralidade passa a ser uma característica dominante, haja vista a maior possibilidade da procura e/ou do ingresso de discentes oriundos de outras localidades do país que não predominantemente da região geográfica em que a IES se situa.

Outro desafio diz respeito à aceitabilidade institucional de que conteúdo pedagógico do processo seletivo perderá a sua característica conteudística regional, a fím de que não se contraponha a uma lógica nacional de seleção.

O terceiro desafio que se vislumbra refere-se às demandas estudantis por necessidades basilares de fixação na região em que a IES está localizada, implicando mais esforços em políticas de assistência estudantil, especialmente aquelas empenhadas em mitigarem as necessidades de moradia e alimentação, dado que muitos discentes que deslocarão poderão não dispor das condições econômicas minimamente necessárias para viverem distantes dos seus lugares de origem.

Atenta a esses desafios, a UESB vem adotando como estratégia a hibridez no processo seletivo, ou seja, valendo-se tanto do tradicional vestibular quando do SiSU, bem como, pautando continuamente o tema nas assembleias promovidas pelo seu Conselho Superior, a fim de conseguir administrar os impactos numa escala ainda reduzida e estabelecer um modus operandi para lidar com um futuro que impactará na sua política de gestão administrativa, financeira e pedagógica.

\section{Considerações finais}

Das análises realizadas e dos resultados obtidos, constata-se que as políticas de permanência expressas, no PNE, como inseparáveis das políticas de acesso, inclusão, ações afirmativas e assistência estudantil, têm sido, do ponto de vista discursivo da gestão institucional, uma preocupação da UESB. Prova disso, é a aprovação e vigência, praticamente em concomitância, de três resoluções na universidade aprovadas no ano de 2008 e que orientam o sistema de reserva de vagas e cotas adicionais, o programa de ações afirmativas e o programa de assistência estudantil. Posterior a essas resoluções, a adesão ao SiSU, em 2012, as fortaleceu, sobretudo, no que diz respeito ao incentivo financeiro propiciado pelo PNAES às IES que o aderiram como forma de seleção dos seus estudantes.

A adesão ao SiSU na UESB teve como principais motivos estimuladores a possibilidade dos recursos financeiros provenientes do PNAES, a bandeira da democratização do acesso à Universidade, já que, por seu caráter nacional, possibilitaria ao candidato concorrer a um curso em qualquer lugar do Brasil, e a isenção da taxa de inscrição no exame seletivo respectivo, o 
Enem, para a maioria dos candidatos. Mas, ao mesmo tempo, trouxe preocupações institucionais concernentes ao possível aumento do número de evasões, cujos candidatos, em sua maioria, não seriam oriundos da região geográfica de abrangência da Universidade.

Contudo, no decorrer da sua execução, verificou-se que, quanto aos motivos estimuladores para a adesão ao SiSU: o recurso do PNAES não chega, à universidade, juntamente com o ingresso dos alunos, e nem atende somente esse público específico, o que exige que a instituição, por recursos próprios e isoladamente, tente garantir a permanência e a assistência por um longo período de tempo; não houve ampliação do número de vagas e a demanda aumentou, uma vez que, a concorrência passou a ser nacional, tornando questionável essa democratização do acesso à Universidade. E, quanto às preocupações iniciais da instituição sobre a adesão ao SiSU, apreende-se que: o índice de evasão no SiSU não é expressivamente maior do que o registrado no Vestibular, processo seletivo tradicionalmente adotado pela UESB, e a origem dos ingressantes é, majoritariamente, do estado da Bahia.

Apreende-se, assim, que a inserção do SiSU como forma paralela de seleção ao tradicional vestibular adotado pela UESB desestabilizou um imaginário que se tinha em relação a um processo nacional com o qual, teoricamente, se angariaria vultuosas contribuições financeiras; que democratização de acesso é mais que diversificação nas formas de ocupação, visto que, apenas diversificar não significa ampliar o número de ingressos; que evasão não é definitivamente um fenômeno objetivo e que, portanto, não se explica meramente por um viés de análise geocartográfico; e, por fim, a certeza de que vive-se uma sociedade glocal ${ }^{2}$, termo que vem sendo adotado, segundo Khondker (2004), desde o ano de 1980 em alusão a uma visão global inerente à sua materialização em condições locais, pelo que, a adoção de uma forma de seleção nacional é uma característica inevitável a esse modelo de sociedade, no entanto, essa mesma sociedade quando se globaliza coloca em evidência a sua heterogeneidade.

Pelo exposto, democratizar o acesso à universidade não se restringe à adesão de mais uma forma de seleção e, nem tão pouco, deve representar um risco à autonomia universitária no que se refere à elaboração e direcionamento das suas políticas internas. A política de acesso à universidade não pode, portanto, ser moeda de troca para a garantia das ações de permanência e assistência estudantil. Pelo contrário, o direito às políticas de permanência e assistência estudantil está previsto não só em resoluções e leis, como na própria Constituição Federal brasileira, cuja finalidade é permitir que estudantes, principalmente aqueles mais

\footnotetext{
${ }^{2}$ Esse termo foi proposto a partir da expressão japonesa dochakuka, que em português significa dizer aquele que vive em sua própria terra.
} 
desfavorecidos socioeconomicamente, tenham a oportunidade de ingressar, permanecer e concluírem os seus cursos.

\section{Referências}

BAHIA. Resolução CONSEPE $\mathbf{n}^{\mathbf{0}} \mathbf{3 6}$ /2008. Dispõe sobre o estabelecimento do Programa de Ações Afirmativas da UESB, define seus princípios, objetivos e dá outras providencias. Vitória da Conquista, 2008a. Disponível em: http://www2.uesb.br/prae/wpcontent/uploads/2014/08/36-Programa-de-A\%C3\%A7\%C3\%B5es-Afirmativas.pdf. Acesso em: 17 dez. 2017.

BAHIA. Resolução CONSEPE $\mathbf{n}^{0}$ 37/2008. Dispõe sobre o sistema de reserva de vagas e quotas adicionais no processo seletivo para os cursos de graduação da UESB e dá outras providencias. Vitória da Conquista, 2008b. Disponível em:

http://www2.uesb.br/transparencia/uploads/consepe/37\%20-

\%20Reserva\%20de\%20vagas.\%20Cotas.pdf. Acesso em: 17 dez. 2017.

BAHIA. Resolução CONSU no 11/2008. Dispõe sobre o estabelecimento do Programa de Assistência Estudantil da UESB e dá outras providencias. Vitória da Conquista, 2008c. Disponível em: http://aapa.uesb.br/wp-content/uploads/2020/02/Resolu\%C3\%A7\%C3\%A30CONSU-n\%C2\%BA-011.2008-Programa-de-Assist\%C3\%AAncia-Estudantil.pdf. Acesso em: 17 dez. 2017.

BAHIA. Plano de Desenvolvimento Institucional 2013 a 2017. Vitória da Conquista, 2013. Disponível em: http://www2.uesb.br/pdi/arquivos/PDI-UESB-2013-2017.pdf. Acesso em: 17 dez. 2017.

BARDIN, L. Análise de conteúdo. São Paulo: Edições 70, 1991.

BOURDIEU, Pierre. Escritos de educação. Petrópolis: Vozes, 1998.

BRASIL. Decreto $n^{\circ} 5.800$, de 8 de junho de 2006. Dispõe sobre o Sistema Universidade Aberta do Brasil - UAB. Diário Oficial da União, Brasília, DF, 9 jun. 2006. Disponível em: http://www.planalto.gov.br/ccivil_03/_ato2004-2006/2006/decreto/d5800.htm. Acesso em: 20 dez. 2017.

BRASIL. Decreto n 7.234 , de 19 de julho de 2010. Dispõe sobre o Programa Nacional de Assistência Estudantil - PNAES. Diário Oficial da União, Brasília, DF, 20 jul. 2010.

Disponível em: http://www.planalto.gov.br/ccivil_03/_Ato20072010/2010/Decreto/D7234.htm. Acesso em: 20 dez. 2017.

BRASIL. Lei $\mathrm{n}^{\circ}$ 12.711, de 29 de agosto de 2012. Dispõe sobre o ingresso nas universidades federais e nas instituições federais de ensino técnico de nível médio e dá outras providências. Diário Oficial da União, Brasília, DF, 30 ago. 2012. Disponível em: http://portal.inep.gov.br/documents/186968/523064/desigualdade+de+acesso+\%c3\%80+educ a\%c3\%87\%c3\%83o+superior+no+brasil+e+o+plano+nacional+de+educa\%c3\%87\%c3\%83o/ 0977f6b9-281d-48df-aeb2-2e5942dc26d6?version=1.2. Acesso em: 20 dez. 2017. 
BRASIL. Lei no 13.005, de 25 de junho de 2014. Aprova o Plano Nacional de Educação PNE e dá outras providências. Diário Oficial da União, Brasília, DF, 16 jun. 2014.

Disponível em: http://www.planalto.gov.br/ccivil_03/_Ato2011-2014/2014/Lei/L13005.htm. Acesso em: 20 dez. 2017.

BRASIL. Ministério da Educação. Censo da Educação Superior: notas estatísticas 2017. Disponível em:

http://download.inep.gov.br/educacao_superior/censo_superior/documentos/2018/censo_da_e ducacao_superior_2017notas_estatisticas2.pdf. Acesso em: 20 dez. 2017.

BRASIL. Portaria INEP N ${ }^{\circ}$ 945, de 26 de outubro de 2018. Diário Oficial da União, Brasília, DF, 01 nov. 2018. Disponível em: https://www.in.gov.br/materia//asset_publisher/Kujrw0TZC2Mb/content/id/48226046/do1-2018-11-01-portaria-n-945-de26-de-outubro-de-2018-48225963. Acesso em: 20 dez. 2017.

BRASIL. SiSU: Sistema de Seleção Unificada. Brasília, DF, 2017. Disponível em: http://www.sisu.mec.gov.br/legislacao. Acesso em: 20 dez. 2017.

CHAUI, Marilena. Escritos sobre a universidade. São Paulo: Edunesp, 2001.

CHAUI, Marilena. A universidade pública sob a nova perspectiva. In: REUNIÃO ANUAL DA ANPED, 26., 2003, Poços de Caldas. Anais... Poços de Caldas, 2003. Conferência na Sessão de Abertura.

FÁVERO, Maria de Lourdes de Albuquerque. A dimensão histórico-política da nova Lei de Diretrizes e Bases e a Educação Superior. In.: CATANI, Afrânio Mendes (org.). Novas perspectivas nas políticas de educação superior na América Latina no limiar do Século XXI. Campinas, SP: Autores Associados, 1998.

FÁVERO, Maria de Lourdes de Albuquerque. A Universidade no Brasil: das origens à Reforma Universitária de 1968. Educar, Curitiba, n. 28, p. 17-36, 2006.

GIL, Antônio Carlos. Métodos e técnicas de pesquisa social. 6. ed. São Paulo: Atlas, 2008.

GUIMARÃES, A. S. Acesso de negros às universidades públicas. Cadernos de Pesquisa, São Paulo, n. 118, p. 247-268, mar. 2003.

HUNT, F. Dropping out from school: a cross country review of literature. United Kingdom: Centre for International Education, School of Education, University of Sussex, 2008. (Create Pathways to access Research Monograph, n. 16).

KHONDKER, Habibul Haque. Glocalization as globalization: evolution of a sociological concept. e-Journal of Sociology, Bangladesh, v. 1, n. 2, 2004.

LOPES, Roberto Paulo Machado. Universidade pública e desenvolvimento local: uma abordagem a partir dos gastos da Universidade Estadual do Sudoeste da Bahia. 2001. $147 \mathrm{f}$. Dissertação (Mestrado em Economia) - Universidade Federal da Bahia, Salvador, 2002.

MARX, Karl. Grundrisse. São Paulo: Boitempo: Rio de Janeiro: Ed. UFRJ, 2011. 
RANIERI, Nina Beatriz. Autonomia universitária. São Paulo: Edusp, 1994.

TEIXEIRA, A. S. Nota Preliminar. Kessel, Moysés I. A evasão escolar no ensino primário. Revista Brasileira de Estudos Pedagógicos, Brasília, DF, v. 22, n. 56, p. 53-55, 1954.

TEIXEIRA, A. S. Nota Preliminar. In: KESSEL, Moysés I. A evasão escolar no ensino primário. Revista Brasileira de Estudos Pedagógicos, Brasília, DF, v. 22, n. 56, p. 53-55, 1954.

WITTE, K. D. et al. A critical review of the literature on school dropout. Educational Research Review, USA, n. 10, p. 13-28, 2013 